\title{
Correction to: Earthquake recurrence models and occurrence probabilities of strong earthquakes in the North Aegean Trough (Greece)
}

\author{
Christos Kourouklas • Eleftheria Papadimitriou • \\ George Tsaklidis • Vassilios Karakostas
}

Published online: 28 June 2018

(C) Springer Nature B.V. 2018

\section{Correction to: J Seismol}

https://doi.org/10.1007/s10950-018-9763-8

2) The character lambda $(\lambda)$ in equation 1 was missing in the PDF version only. The complete equation 1 is given below.

The original version of this article unfortunately contains mistakes. The mistakes and corrections are described in the following list:

$$
X(t)=\lambda t+\varepsilon(t)
$$

1) Author names were incorrectly presented. The correct format is shown above as well as in the below affiliation section.

The original article has been corrected.

The online version of the original article can be found at https://doi.org/10.1007/s10950-018-9763-8

C. Kourouklas $(\bowtie) \cdot$ E. Papadimitriou $\cdot$ V. Karakostas Geophysics Department, Aristotle University of Thessaloniki, GR54124 Thessaloniki, Greece e-mail: ckourouk1@geo.auth.gr

E. Papadimitriou

e-mail: ritsa@geo.auth.gr

V. Karakostas

e-mail: vkarak@geo.auth.gr

G. Tsaklidis

Statistics and Operational Research Department, School of Mathematics, Aristotle University of Thessaloniki,

GR54124 Thessaloniki, Greece

e-mail: tsaklidi@math.auth.gr 